\title{
Histopathologic Features Associated with Susceptibility and Resistance of Biomphalaria Snails to Infection with Schistosoma mansoni
}

\author{
Claudia Maria C Borges, Cecília Pereira de Souza*, Zilton A Andrade/ ${ }^{+}$
}

\begin{abstract}
Centro de Pesquisas Gonçalo Moniz-Fiocruz, Rua Valdemar Falcão 121, 40295-001, Salvador, BA, Brasil *Centro de Pesquisas René Rachou-Fiocruz, Av. Augusto de Lima 1517, 31190-002, Belo Horizonte, MG, Brasil

Resistance and susceptibility of Biomphalaria snails to Schistosoma mansoni sporocysts occur in different degrees. Histopathology reflects these diferences. In a state of tolerance numerous sporocysts in different stages of differentiation are seen in the absence of host tissue reaction. However extensive diffuse and focal proliferation of amebocytes with sequestration and destruction of many parasitic structures appear in resistant snails. Some snails are totally resistant and when exposed to infecting miracidia may never eliminate cercarie. Sequential histopathological examination has revealed that in such cases the infected miracidia are destroyed a few minutes to $24 \mathrm{hr}$ after penetration in the snail. However, $B$. glabrata that were exposed to $S$. mansoni miracidia and three moths later failed to shed cercariae, exhibited focal and diffuse proliferation of amebocytes in many organs in the absence of pasitic structures. These lesions were similar to those observed in resistant snails that were still eliminating a few cercariae, with the difference that no recognizable sporocystic structures or remmants were present. Histological investigation carried out in similarly resistant B. tenagophila and B. straminea presented essentially normal histologic structures. Only occasionally a few focal proliferative (granulomatous) amebocytic reactions were seen in ovotestis and in the tubular portion of the kidney.

Probably, there are two types of reactions to miracidium presented by totally resistant snails: one would implicate the immediate destruction of the miracidium leaving no traces in the tissues; the other involving late reactions that seem to completely destroy invading sporocysts and leave histological changes.
\end{abstract}

Key words: snails - Schistosoma mansoni - susceptibility - resistance - histopathology

Morphological features of host/parasite relationship have been specially studied in Biomphalaria glabrata submitted to infection with Schistosoma mansoni miracidia (Newton 1952, Barbosa \& Barreto 1960, Pan 1965). It has been demonstrate that miracidia penetrate in susceptible snail and differentiate into sporocysts. These forms exhibit extensive proliferation, remaining viable and active, producing great number of cercariae. However, in highly resistant specimens, penetrating miracidia are quickly recognized and destroyed by means of amebocytes. In some cases, miracidia succeed in invading and developing sporocysts, but some of them are surrounded by amebocytes, forming encapsulating reactions, apparently destroying the parasites. The occurrence of this focal, proliferative, inflammatory reactions vary in number and

${ }^{+}$Corresponding author. Fax: +55-71- 356.4292. E-mail: zilton@server01.cpqgm.fiocruz.br

Received 4 May 1998

Accepted 31 August 1998 intensity from case to case, according to the degree of susceptibility or resistance present, and being reflected in the number of cercariae emmitted by the infected snail. Amebocytes are primitive macrophages that circulate freely within the hemolymph and can accumulate in specific sites around sporocysts forming focal, granulomatous structures. Bayne et al. (1980) demonstrated that amebocytes from highly resistant snails are capable to damage the miracidium tegument and to seriously compromise its viability. However, such amebocyte capacity is variable among several individuals. Several intrinsic and extrinsic factors are able to interfere with the degree of snail susceptibility and/or resistance. Probably, genetic-derived factors play a key role (Richards et al. 1992). It has been demonstrated that the degree of histocompatibility between sporocysts and snails, which sometimes appears to be acquired, can be an important factor (Yoshino \& Bayne 1983, Daminian 1987).

Differences in susceptibility/resistance occur not only intraspecifically (Souza et al. 1995b), but have been demonstrated between different snail 
species, such as B. glabrata, B. tenagophila and B. straminea (Barbosa 1975, Souza et al. 1995a).

Our studies refer to a histopathological investigation of resistant snails, that although submitted to an infection to numerous $S$. mansoni miracidia completely failed to emit cercariae after a three month period (Godoy et al. 1997, Souza et al. 1997).

\section{STUDIES WITH B. GLABRATA}

Histological observation was first concerned with $B$. glabrata. Strongly resistant $B$. glabrata were observed through successive generations during an investigation on genetic influences in resistance. Snails from an F-15 generation experimentally exposed to $S$. mansoni miracidia failed to shed cercariae three months afeter being exposed to miracidia. When submitted to histological examination these snails did not exhibit S. mansoni sporocysts, but insteade presented an unusual and striking picture of amebocyte reactivity (Godoy et al. 1997). This basically consisted of focal and diffuse proliferation of amebocytes, accompanied by an expansion of the extracellular matrix, which sometimes simulated the process of fibrosis seen in vertebrate tissues. The diffuse amebocyte reaction was conspicuously seen in the albumen gland of all the five cases examined and also appeared associated with thickening and increased basophilia (calcification) of the amorphous secretion material accumulated in the ducts and acini of the albumen gland, which were lined by disintegrating epi- thelial cells. A collar of amebocyte proliferation and matrix thickening was frequently seen around the ducts and tubes, especially at the external coat of the digestive tube (esophagus and intestines) and around the acini of the nidamental gland. A few scattered areas of focal thickening of the stroma appeared amongst the digestive glands and in the ovotestis (Fig. 1). Focal reaction frequently assumed a granuloma-like apperance. Encapsulating lesions were especially observed at the tubular and sacular portions of the kidneys. They were also seen within the connective tissue bordering the mantle cavity, but were rare in the foot and other areas of the anterior portion of the snail. These reactions were formed by amebocytes, fibrils and fibers concentrically disposed around a center area in which a few small irregular basophilic granules were sometimes seen (Fig. 2). The possibility that such granules represented sporocysts remnants could not be ruled out. Of course the lesions just described could be caused by an associated infection, unrelated to $S$. mansoni. An attempt was made to rule out this possibility. Normal snails of the same age and maintained under the same conditions as the exposed ones were submitted to histological examination. No similar changes were seen in them.

Although the possibility of auto-cure has been mentioned in $S$. mansoni-infected snails (Lie et al. 1980), no similar histological picture of amebocyte reactivity was described in snails exposed to miracidia and that subsequently failed to eliminate cercariae.

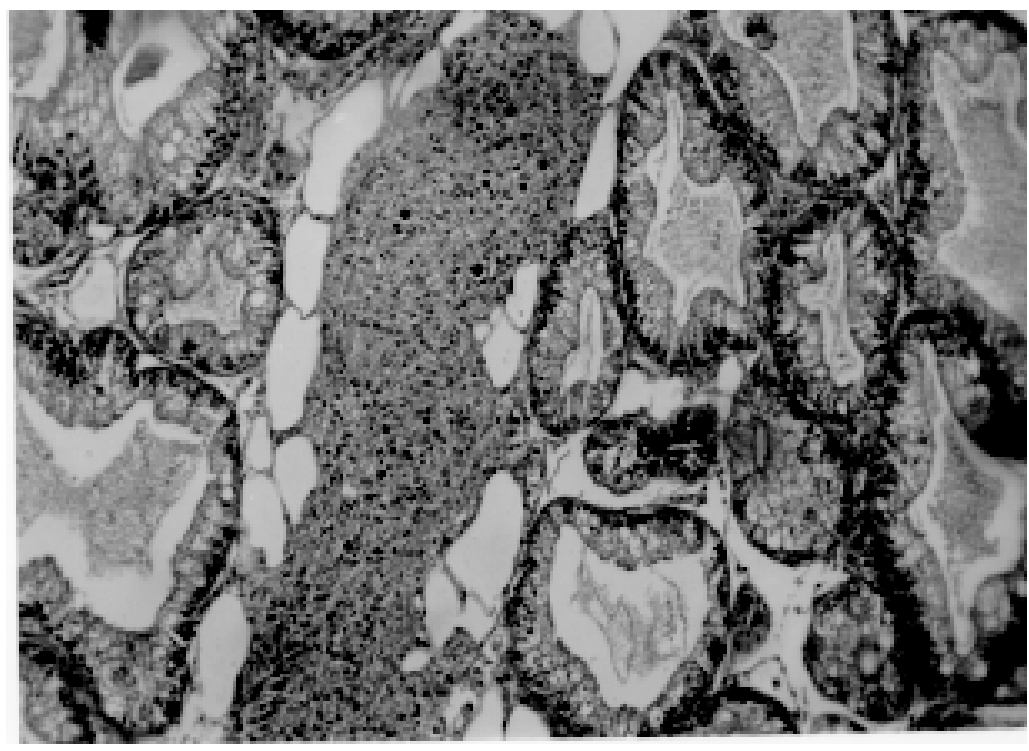

Fig. 1: a large band of proliferating amebocytes appears in between digestive glands of a Biomphalaria glabrata submitted to miracidial exposure but that did not shed cercariae after a three month period. Hematoxylin and Eosin, $100 \mathrm{X}$. 


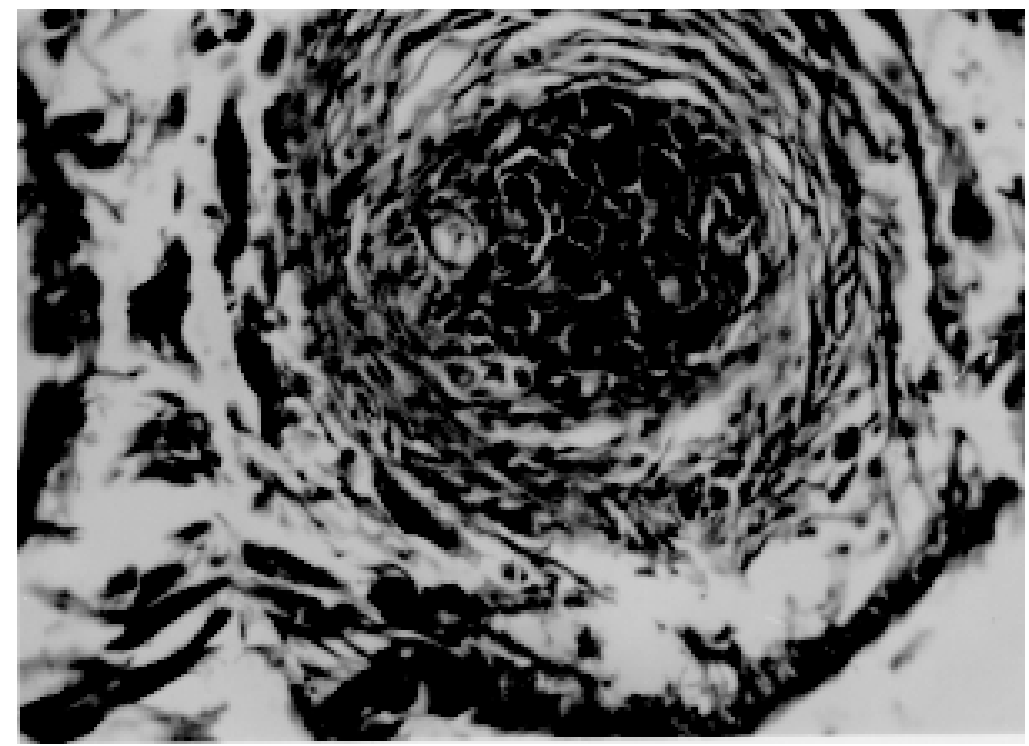

Fig. 2: an encapsulated focal reaction in the region of the mantle collar, seen in Biomphalaria glabrata that failed to eliminate cercariae after being exposed to Schistosoma mansoni miracidia. There is a concentric lamination of fibers at the periphery of the granulomatous lesions and dark stained cellular debris at the center. Hematoxylin and Eosin, $200 \mathrm{X}$.

The histological changes were thus seggestive of sequelae left by the apparently complete destruction of sporocysts. Therefore, strong snail immunity can be raised during the course of infection to eliminate the parasite. This would also place present findings as one pole of snail reactivity toward $S$. mansoni invasion, the other being represented by the complete tolerance seen in some extremely susceptible snails (Guimarães et al. 1997).

The next step was to investigate whether such tissue changes were also present in other snail species, which are naturally more resistance to $S$. mansoni invasion than B. glabrata.

\section{STUDIES WITH B. TENAGOPHILA AND B. STRAMINEA}

B. tenagophila and B. straminea from the State of Minas Gerais, Brazil, were individually exposed to 50 miracidia of $S$. mansoni (Souza et al. 1995b, 1997). The strain used was the SJ-strain which is better adapted to B. tenagophila snails (Paraense $\&$ Correa 1981). Those which failed to shed cercariae up to a period of three months were submitted to histological examination. As before, the same technique of Bouin's fluid fixation and embedding in paraffin was used. Sections were routinely stained with hematoxylin and eosin.

Although numerous sporocysts and foci of amebocyte proliferation were detected in those snails shedding great number of cercariae, no viable sporocysts were found in histological sections taken from any of the exposed snails that failed to eliminate cercariae. Focal inflammatory tissue reactions were found rarely and in only two specimens each to B. tenagophila and B. straminea. In ovotestis and renal tubular region in the case of $B$. tenagophila (Fig. 3) and only once, in the region of an atrophic ovotestis of B. straminea (Fig. 4). These reactions were similar to those found encircling or in close vicinity of proliferating sporocysts in snails shedding cercariae. However, no evident sporocystic structures were identified in any of the foci or in any other part of the snails that failed to eliminate cercariae. Normal non-infected snails of the two species examined showed essentially normal histology. No focal or diffuse inflammatory reaction was ever observed.

\section{DISCUSSION}

By observing tissue changes in snails that were exposed to miracidial infection but that failed later on to shed cercariae, considerable differences were noted among snail species. A common finding was the absence of parasitic structures, but while $B$. glabrata frequently exhibited focal and diffuse amebocyte proliferation in several organs, only a few and occasional focal amebocyte reactions were seen in B. tenagophila and B. straminea. The amebocyte reactions seen probably represented the aftermath of sporocyst destruction (Godoy et al. 1997). 


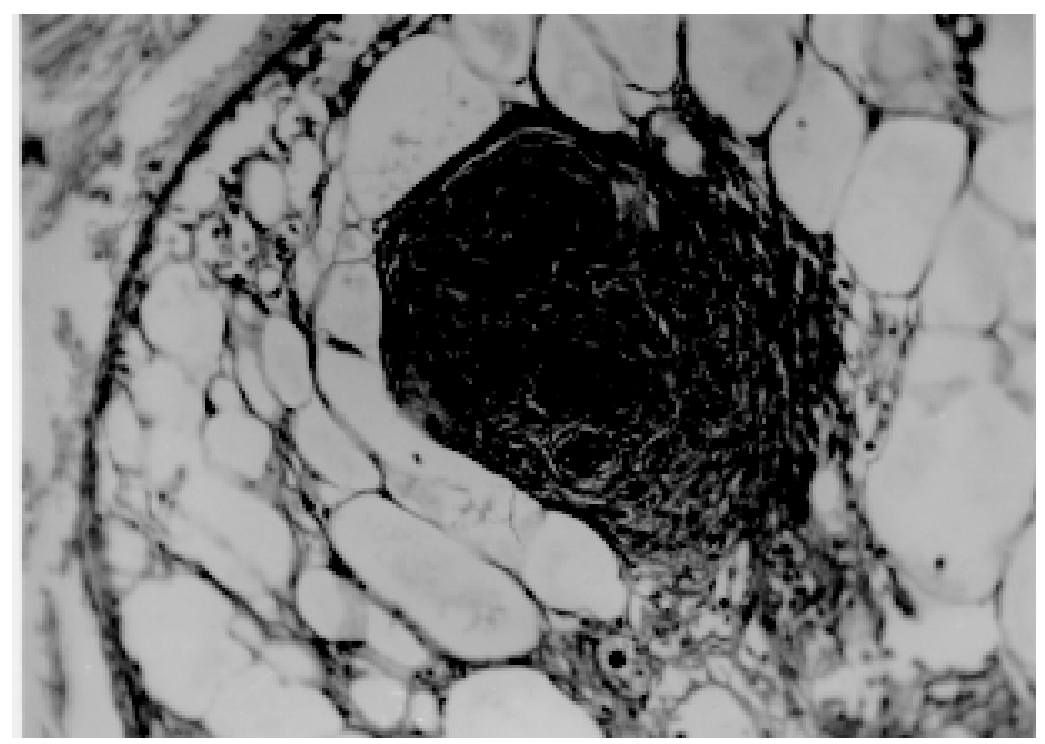

Fig. 3: focal collection of amebocytes found in an atrophic ovotestis of Biomphalaria tenagophila that failed to shed cercariae. Hematoxylin and Eosin, $160 \mathrm{X}$.

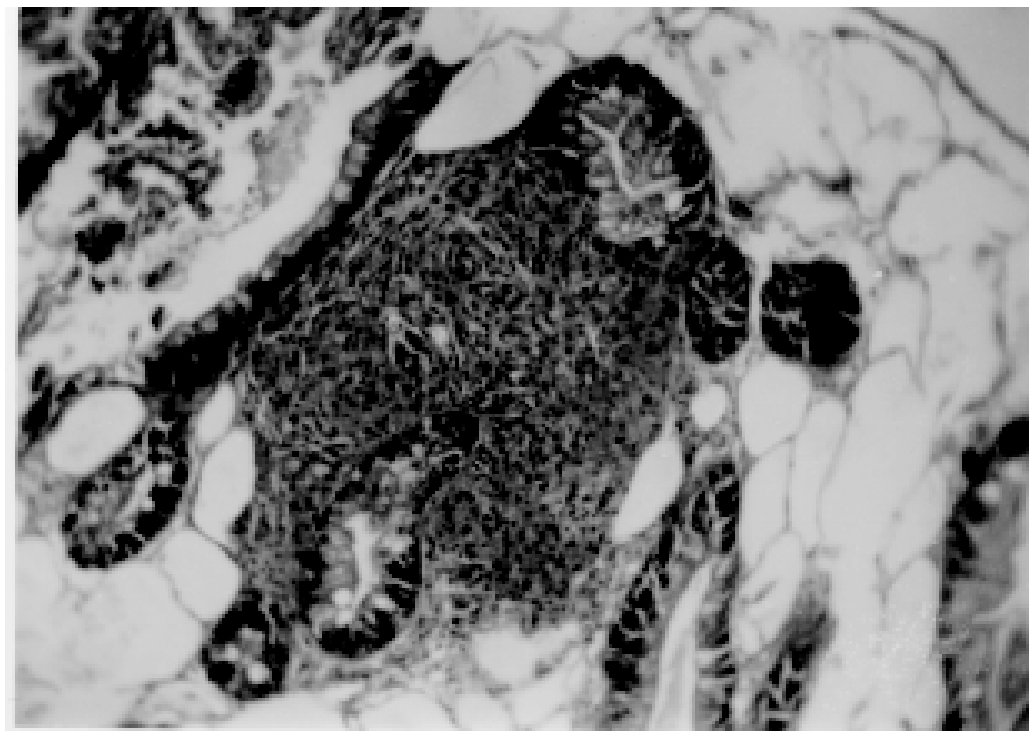

Fig. 4: a collection of amebocytes, similar to that seen in Fig. 3, but found in the region of the digestive glands of Biomphalaria straminea resistant to Schistosoma mansoni miracidia. Hematoxylin and Eosin, $160 \mathrm{X}$.

This kind of delayed-developed resistance probably represents an alternative and novel kind of host defense mechanism against $S$. mansoni miracidia, in spite of evidences suggesting that $S$. mansoni sporocysts can sometimes better develop their ability to interfere with the defense mechanism of the snail as they grow older (Lie et al. 1980). Thus, the amebocytic reaction that is already known to be partially inhibitory of sporocyst development, appears sometimes to be totally effective.

Therefore, protection against miracidial invasion could be provided by at least two mechanisms. One being represented by the already known example of direct miracidium destruction which oc- 
curs soon after penetration. Loker et al. (1982) found miracidium amebocyte contact within $3 \mathrm{hr}$ and phagocytosis of sporocysts microvilli and pieces of tegument within $7.5 \mathrm{hr}$, while extensive pathology was demonstrated within $24 \mathrm{hr}$ and by $48 \mathrm{hr}$ only scattered remnants of sporocysts remained. The other mechanism would be represented by the one here postulated, that is, a successful mounting of a destructive reaction when several sporocysts have already disseminated throughout the snail tissues.

This second mechanism appeared frequently and widespread in B. glabrata; it was only rarely seen in the other two species. Strongly resistant $B$. tenagophila and $B$. straminea rather utilize the first mechanism, the killing of invading miracidia would leave no residual changes.

The finding of tissue reaction in the absence of sporocystic structure does not mean that $S$. mansoni infection has been completely erradicated. It is possible that a few undamaged sporocysts can remain viable in some remote location within the snails. That such situation exists is indicated by the emergency of cercariae from highly resistant snails up to nine month interval following miracidial exposure (CP Souza, unpublished data).

\section{REFERENCES}

Barbosa FS 1975. Survival and cercaria production of Brazilian Biomphalaria glabrata and Biomphalaria straminea infected with Schistosoma mansoni. J Parasitol 61: 151-152.

Barbosa FS, Barreto AC 1960. Differences in susceptibility of a Brazilian strain of Australorbis glabratus to Schistosoma mansoni. Exp Parasitol 9: 137-140.

Bayne CJ, Buckley PM, Dewan PC 1980. Macrophagelike hemocytes of resistant Biomphalaria glabrata are cytotoxic for sporocysts of Schistosoma mansoni in vitro. J Parasitol 66: 413-419.

Damian RT 1987. Molecular mimicry revisited. Parasitol Today 3: 263-266.

Godoy A, Souza CP, Guimarães CT, Andrade ZA 1997. Unusual histological findings in Biomphalaria glabrata with high degree of resistance to Schistosoma mansoni miracidia. Mem Inst Oswaldo Cruz. 92: 121-122.

Guimarães CT, Soares DM, Andrade ZA, Souza CP 1997. Resistência de Biomphalaria glabrata à infecção pelo Schistosoma mansoni: variações no período pré-patente e na compatibilidade. Rev Soc Bras Med Trop 30: 273-278.

Lie KJ, Jeong KH, Heyneman D 1980. Tissue reaction induced by Schistosoma mansoni in Biomphalaria glabrata as targets of Echinostoma mediate interference with host snails resistance to Schistosoma mansoni. Exper Parasitol 62: 149-154.

Newton WL 1952. The comparative tissue reaction of two strains of Australorbis glabratus to infection with Schistosoma mansoni. J Parasitol 38: 362-366.

Pan CT 1965. Studies on the host-parasite relationship between Schistosoma mansoni and the snail Australorbis glabratus. Am J Trop Med Hyg 14: 931975.

Paraense WL, Correa LR 1981. Observations of two biological races of Schistosoma mansoni. Mem Inst Oswaldo Cruz 76: 287-291.

Richards CS, Knight M, Lewis FA 1992. Genetics of Biomphalaria glabrata and its role on the outcome of Schistosoma mansoni infection. Parasitol Today 8: 171-174.

Souza CP, Janotti-Passos LK, Freitas JR 1995a. Degree of host-parasite compatibility between Schistosoma mansoni and their intermediate molluscan host in Brazil. Mem Inst Oswaldo Cruz 90: 5-10.

Souza CP, Cunha RCP, Andrade ZA 1995b. Development of Schistosoma mansoni in Biomphalaria tenagophila, Biomphalaria straminea and Biomphalaria glabrata. Rev Inst Med Trop São Paulo 37: 201-206.

Souza CP, Borges CC, Santana AG, Andrade ZA 1997. Comparative histopathology of Biomphalaria glabrata, B. tenagophila and B. straminea with variable degrees of resistance to Schistosoma mansoni miracidia. Mem Inst Oswaldo Cruz 92: 517-522.

Yoshino TP, Bayne CP 1983. Mimicry of snail host antigens by miracidia and primary sporocysts of Schistosoma mansoni. Parasite Immunol 8: 317-328. 
122 Snail Histopathology - Claudia C Borges et al. 